\title{
Pemberdayaan Masyarakat Melalui PENKES (Pendidikan dan Kesehatan) untuk Meningkatkan Derajat Kesehatan Masyarakat
}

\author{
Linda Suwarni \\ Universitas Muhammadiyah Pontianak \\ linda.suwarni@unmuhpnk.ac.id \\ Selviana \\ Universitas Muhammadiyah Pontianak \\ selviana@unmuhpnk.ac.id \\ Eko Sarwono \\ Universitas Muhammadiyah Pontianak \\ ekosarwono18@yahoo.com \\ Ufi Ruhama \\ Universitas Muhammadiyah Pontianak \\ ufhie_r@yahoo.com
}

\begin{abstract}
Abstrak
Masyarakat di wilayah pemekaran Kalimantan Barat masih berpendidikan minim (bahkan masih ada yang masih buta huruf) dan masalah kesehatan yang selalu ada, diantaranya diare. Faktor yang melatarbelakangi diantaranya belum sadarnya masyarakat dalam menerapkan perilaku hidup bersih dan sehat, dan rendahnya cakupan ASI Eksklusif. Selain itu, masih minimnya pendidikan yang ada.

Dalam upaya mengatasi permasalahan tersebut maka solusinya adalah melalui Pemberdayaan Masyarakat melalui PenKes (Pendidikan dan Kesehatan) untuk meningkatkan derajat kesehatan masyarakat, antara lain dengan: (a) Penyuluhan Perilaku Hidup Bersih dan Sehat (PHBS), melalui lokakarya mini kesehatan, promosi berbagai upaya kesehatan, dan pelatihan serta praktek pembuatan teknologi air bersih dengan saringan air bertingkat, (b) Peningkatan Pendidikan Masyarakat melalui pembentukan dan pelatihan kader pendidik "Pondok Pintar", pelatihan pembuatan kolase, mozaik dan montase dari bahanbahan sederhana, serta pelatihan metode morance. Kegiatan ini dilakukan melalui pendampingan masyarakat selama 2 bulan. Metode yang digunakan adalah pendampingan dan penyuluhan serta pelatihan.

Hasil program pengabdian ini menunjukkan bahwa masyarakat mempunyai pengetahuan dan kesadaran untuk berperilaku hidup bersih dan sehat. Selain itu, terbentuknya "pondok pintar' dan kader pendidik dalam upaya memberantas buta huruf. Diperlukan dukungan yang kontinue dari pemerintahan setempat agar program yang ada dapat berjalan terus.
\end{abstract}

Kata Kunci: Pendidikan, Kesehatan, Pemberdayaan Masyarakat 


\section{Jurnal Abdimas Mahakam \\ https://journal.uwgm.ac.id/index.php/abdimasmahakam \\ Online ISSN : 2549-5755 \\ Januari 2018, Vol. 2 No. 1}

\section{Pendahuluan}

Kalimantan Barat merupakan salah satu propinsi dengan IPM menduduki peringkat ke 30 diantara 33 propinsi di Indonesia. Hal ini menunjukkan bahwa daerah ini membutuhkan peningkatan di semua sektor, di antaranya adalah sektor kesehatan, pendidikan dan ekonomi. Pembangunan di segala bidang di Kabupaten Kubu Raya perlu terus ditingkatkan karena kabupaten ini merupakan kabupaten pemekaran dari Kabupaten Pontianak, sehingga banyak sektor yang masih perlu diperhatikan (Profil Kecamatan Sungai Kakap, 2015). Salah satunya adalah pada sektor kesehatan dan pendidikan.

Masih adanya kasus kematian pada balita yang disebabkan oleh penyakit diare, tingginya kasus ISPA (Infeksi Pernapasan Akut) dan TB (Tuberkulosis), sanitasi lingkungan yang buruk, cakupan ASI Ekslusif, persalinan oleh tenaga kesehatan, dan PHBS (perilaku hidup bersih dan sehat) yang rendah, merupakan permasalahan dalam bidang kesehatan daerah ini. Hal ini dapat terjadi karena masih banyak masyarakat yang minum air hujan secara langsung tanpa dimasak terlebih dahulu. Selain itu, penyakit saluran pernapasan masih tinggi, diantaranya ISPA dan TB Paru yang masuk dalam urutan 10 penyakit terbesar.

Angka kejadian penyakit berbasis lingkungan juga mengalami peningkatan. Pada tahun 2015 angka kejadian penyakit diare pada balita mencapai 56\% dan 2 orang diantaranya meninggal dunia, begitupula dengan penyakit kecacingan yang mencapai $63 \%$ yang umumnya terjadi pada anak SD, dan penyakit kulit $72 \%$. Masalah kesehatan lain yang ada, diantaranya adalah masih rendahnya cakupan pelayanan kesehatan seperti imunisasi 78,6\%, ASI Ekslusif (62\%), persalinan ke tenaga kesehatan (87,3\%), PHBS (Perilaku Hidup Bersih dan Sehat) serta sanitasi lingkungan yang kurang baik Sarana Air Bersih (58\%), rumah sehat (67,9\%), dan jamban sehat (70,7\%) (Profil Puskesmas Sungai Kakap, 2015). Sanitasi lingkungan yang buruk merupakan salah satu penyebab masalah kesehatan yang terjadi (Montgomery, 2007; Suwarni, Selviana, dan Fachri, 2016; Permatasari dan Sinuraya, 2017). 


\section{Jurnal Abdimas Mahakam \\ https://journal.uwgm.ac.id/index.php/abdimasmahakam \\ Online ISSN : 2549-5755 \\ Januari 2018, Vol. 2 No. 1}

Di bidang pendidikan,umumnya masyarakat berpendidikan SMP (45\%), dan SD (20\%), SMA (25\%), dan PT (10\%). Rata-rata waktu pendidikan masyarakat di wilayah tersebut relatif pendek jika dibandingkan dengan wilayah lainnya. Bahkan, masih ada yang buta huruf. Sarana dan prasarana pendidikan di wilayahinimasih minim, semakin memparah keadaan ini. Banyak anak-anak usia SD belum bisa membaca dan menulis dengan lancar. Selain itu, PAUD yang di berada diwilayah ini adalah PAUD yang dibangun oleh masyarakat dengan guru yang berpendidikan bukan sarjana Pendidikan PAUD. Selama ini yang mengajar PAUD adalah siswa SMA yang baru tamat sekolah. Hal ini mengakibatkan terbatasnya kemampuan mereka dalam memberikan pendidikan, dan keterampilan kepada anak-anak.

Berdasarkan hal tersebut di atas, perlu dilakukan Pemberdayaan Masyarakat Melalui PENKES (Pendidikan dan Kesehatan) dalam Rangka Meningkatkan Derajat Kesehatan di Wilayah Pemekaran Kalimantan Barat. Oleh karena itu, perlunya pemberdayaan masyarakat, bersama tokoh masyarakat bekerjasama dengan lintas sektor untuk pembangunan di bidang sektor kesehatan, dan pendidikan.

\section{Metode}

Kegiatan pengadian kepada masyarakat ini dilaksanakan selama dua (2) bulan di Kecamatan Sungai Kakap. Peserta pengabdian adalah masyarakat yang ada di Desa Punggur dan Kalimasdi Kecamatan Sungai Kakap.

Metode kegiatan yang dilaksanakan, yaitu pendampingan dan pelatihan. Dalam bidang kesehatan dilakukan melalui promosi Perilaku Hidup Bersih dan Sehat untuk meningkatkan pengetahuan dan pemahaman masyarakat terkait pentingnya hidup bersih dan sehat. Selain itu, juga dilakukan pelatihan dan pendampingan pembuatan teknologi saringan air bersih sederhana, sosialisasi tanaman obat keluarga (TOGA). Sedangkan dalam bidang pendidikan dilakukan melalui pendampingan dalam pembentukan pondok pintar, pelatihan pada kader pendidik, dan pendampingan dalam pengelolaan pondok pintar. 


\section{Jurnal Abdimas Mahakam \\ https://journal.uwgm.ac.id/index.php/abdimasmahakam \\ Online ISSN : 2549-5755 \\ Januari 2018, Vol. 2 No. 1}

\section{Hasil dan Pembahasan}

Peningkatan Perilaku Hidup Bersih dan Sehat, meliputi: Loka Karya Mini di tingkat kecamatan dan desa; Promosi kesehatan meliputi penyuluhan tentang PHBS (Perilaku Hidup Bersih dan Sehat) dan GERMAS (Gerakan Masyarakat Sehat), sosialisasi jajanan sehat, sarana air bersih, kesehatan reproduksi, dan sanitasi lingkungan; Penyuluhan Perilaku Hidup Bersih dan Sehat (PHBS) Program perilaku hidup bersihdan sehat ini difokuskan pada kegiatan penyuluhan, demonstrasi dan FGD (Focus Froup Discussion) pada 3 sasaran utama yaitu; siswa SD, SMP/MTs, dan Masyarakat umum. Kegiatan tersebut dilaksanakan di SDN 41Sui. Kakap, SDN 05 Sui.Kakap, SDN 02 Sui.Kakap, SDN 32 Sui.Kakap, SDN 22 Sui.Kakap, SMPN 05 Sui.Kakap dan SMPN 03 Sui Kakap. Program perilaku hidup bersih dan sehat ini meliputi dua kegiatan utama yaitu cara cuci tanganyang baik dan senam sehat. Pada demonstrasi dan penyuluhan yang dilakukan di masyarakat, Majelis Ta'lim dan kader posyandu langsung dibekali dengan perlengkapan PHBS seperti modul materi Toga dan pamflet mengenai KB dan ASI Ekslusif di setiap posyandu.
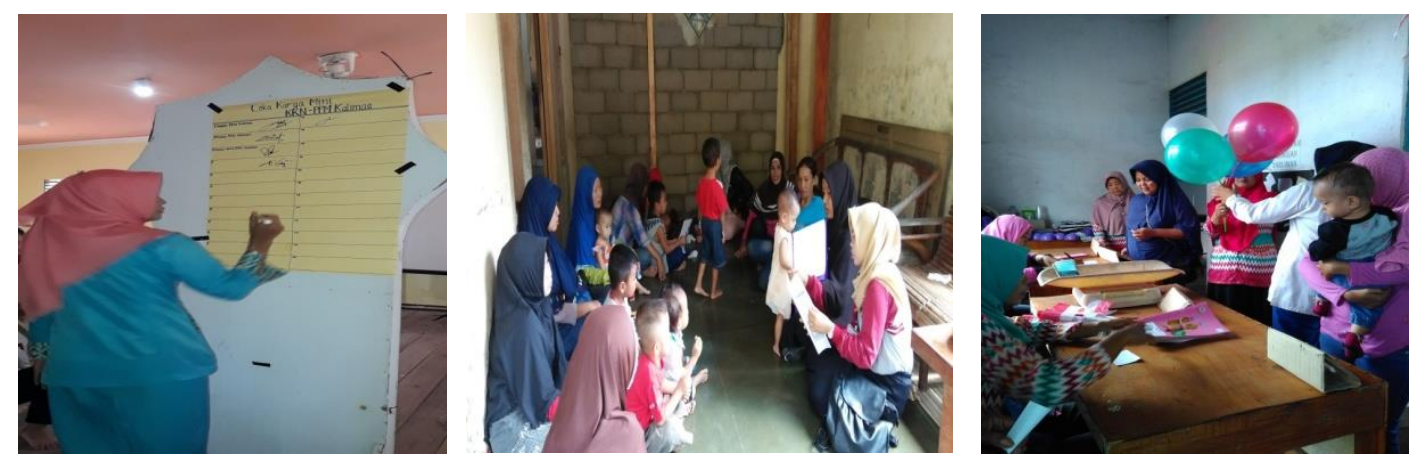

Gambar 1. Lokakarya mini dan penyuluhan PHBS

Hasil kegiatan ini meningkatkan pemahaman masyarakat tentang pentingnya perilaku hidup bersih dan sehat, dan dapat menumbuhkan kesadaran masyarakat untuk berperilaku yang sehat. Hal ini dapat dilihat dari evaluasi setelah dilakukan sosialisasi dan penyuluhan tentang PHBS. Dalam proses ini juga terlihat masyarakat yang mengikuti mempunyai rasa ingin tahu yang besar dan selalu bertanya. Selain itu, juga terbentuk komitmen dari masyarakat yang terlibat untuk mulai menerapkan perilaku hidup bersih dan sehat di lingkungan keluarga dan 


\section{Jurnal Abdimas Mahakam \\ https://journal.uwgm.ac.id/index.php/abdimasmahakam \\ Online ISSN : 2549-5755 \\ Januari 2018, Vol. 2 No. 1}

tempat tinggal mereka. Hasil kegiatan pengabdian ini sejalan dengan beberapa penelitian terdahulu yang menunjukkan bahwa ada pengaruh yang positif intervensi yang berupa penyuluhan melalui media film dalam meningkatkan pengetahuan dan kesadaran dalam berperilaku hidup bersih dan sehat (Yuswatiningsih, 2016; Mawan, Indriwati, dan Suhadi, 2017; Selviana, Suwarni, dan Fahri, 2018).

Sosialisasi pemanfaatan lahan pekarangan untuk tanaman obat keluarga (TOGA) dan hidroponik. Tanah yang terdapat di wilayah Desa Punggur Besar cenderung kurang subur dengan komposisi terbesarnya adalah tanah liat. Oleh karena itu, budidaya hidroponik sangat cocok dilaksanakan di daerah tersebut. Desa Punggur Besar Khususnya Pondok Pesantren Miftahul Ulum kecamatan Sungai Kakap merupakan tempat yang dipilih sebagai lokasi pelatihan dan budidaya. Kegiatan tersebut melibatkan para remaja yang ada di Wilayah Kecamatan Sungai Kakap. Selain itu, pemilihan pondok pesantren sebagai sasaran sosialisasi dan pembuatan hidroponik agar para santri mau dan mampu memenuhi kebutuhan gizi mereka secara mandiri melalui hidroponik.

Di Desa Kalimas, Punggur Besar dan Punggur Kecil terdapat tanaman obat keluarga (TOGA) tetapi masyarakat disana tidak memanfaatkan tanaman TOGA tersebut untuk proses pengobatan dikarenakan kurangnya pengetahuan masyarakat mengenaimanfaat tanaman obat keluarga tersebut. Oleh karena itu, upaya meningkatkan pengetahuan tentang pemanfaatan tanaman TOGA dimulai dengan sosialisasi TOGA, penataan teknik budidaya tanaman yang dapat dimanfaatkan sebagai obat. Upaya tersebut dilakukan membuat tempat percontohan budidaya TOGA dengan memasukan ilmu landscape kedalamnya.

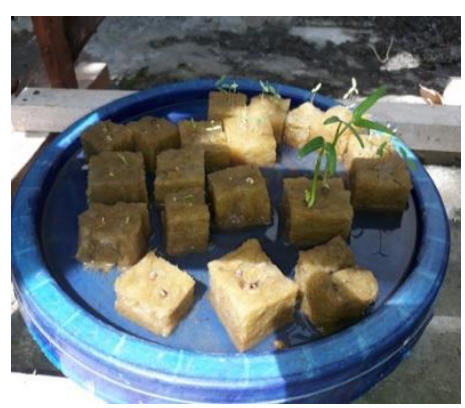

Gambar 2. Sosialisasi

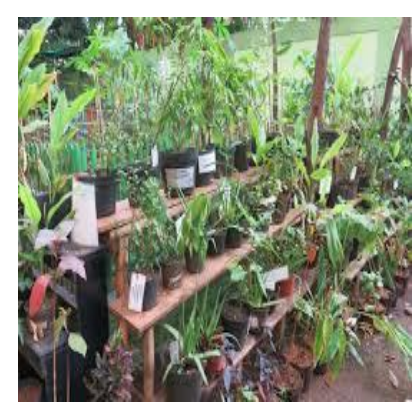

pemanfaatan

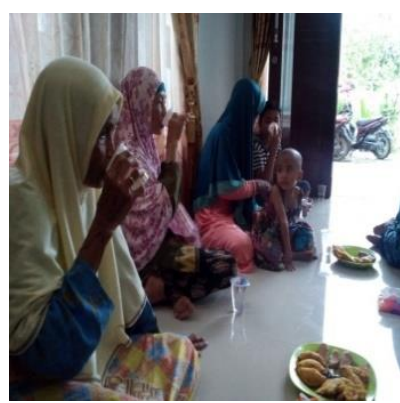

lahan

pekarangan untuk tanaman obat keluarga (Toga) dan hidroponik 


\section{Jurnal Abdimas Mahakam \\ https://journal.uwgm.ac.id/index.php/abdimasmahakam \\ Online ISSN : 2549-5755 \\ Januari 2018, Vol. 2 No. 1}

Kegiatan ini dilaksanakan di posyandu Desa Punggur, posyandu Desa Punggur Besar dan ibu-ibu PKK Desa Punggur ibu-ibu dan remaja maupun pemuda yang ada di Kecamatan Sungai Kakap. Kegiatan diawali dengan sosialisasi terhadap jenis jenis tanaman obat keluarga yang mudah didapatkan dan belum tahu secara mendalam khasiat dari tanaman tersebut. Setelah penyuluh, ibu-ibu dan remaja maupun pemuda mendata tanaman obat yang berada di sekitar desa mereka masing-masing yang selanjutnya dikumpulkan untuk ditanam di lingkungan sekitar setelah itu mereka diberikan buku panduan penggunaan TOGA yang telah disusun.

Peningkatan pendidikan dalam upaya mendukung program wajib belajar pemerintah (12tahun), meliputi: Penyuluhan Pondok Pintar padaAnak sekolah tingkat SD, SMP/MTs dan SMA/SMK merupakan sasaran utama dari kegiatan penyuluhan pondok pintar. Kegiatan ini berbentuk penyuluhan yang dikhususkan pada penataan ruangan pondok pintar di desa Punggur Besar dan meningkatkan minat baca anak serta kegiatan penyuluhan dilakukan di pondok pintar Desa Punggur Besar. Setelah mengikuti penyuluhan anak-anak termotivasi untuk meningkatkan minat bacanya baik dimana pun mereka berada. Dengan penataanruangan yang menarik dapat meningkatkan minat anak untuk selalu berkunjung ke pondok pintar Desa Punggur Besar. Selain itu juga diadakan pelatihan Pembuatan Media Terlaksananya Pelatihan Pembuatan media montase, kolase, meronce, mozaik finger painting dan maket terbuat dari bahan - bahan sederhana, seperti ranting - ranting,kertas origami, majalah/koran bekas, daun kering, pasir dan ampas kelapa. Sasaran kegiatan pelatihan pembuatan media yaitu guru PAUD \& TK se-kecamatan Sungai Kakap. Metode ini dipilih untuk meningkatkan pengetahuan dan keterampilan guru dan anak PAUD tentang keterampilan montase, kolase, mozaik, montase, finger painting dan maket dari bahan - bahan sederhana, seperi ranting - ranting, kertas origami. Dengan demikianakan Meningkatkan Kreativitas Guru Dan Anak PAUD Di Kecamatan Sungai Kakap. 


\section{Jurnal Abdimas Mahakam \\ https://journal.uwgm.ac.id/index.php/abdimasmahakam \\ Online ISSN : 2549-5755 \\ Januari 2018, Vol. 2 No. 1}
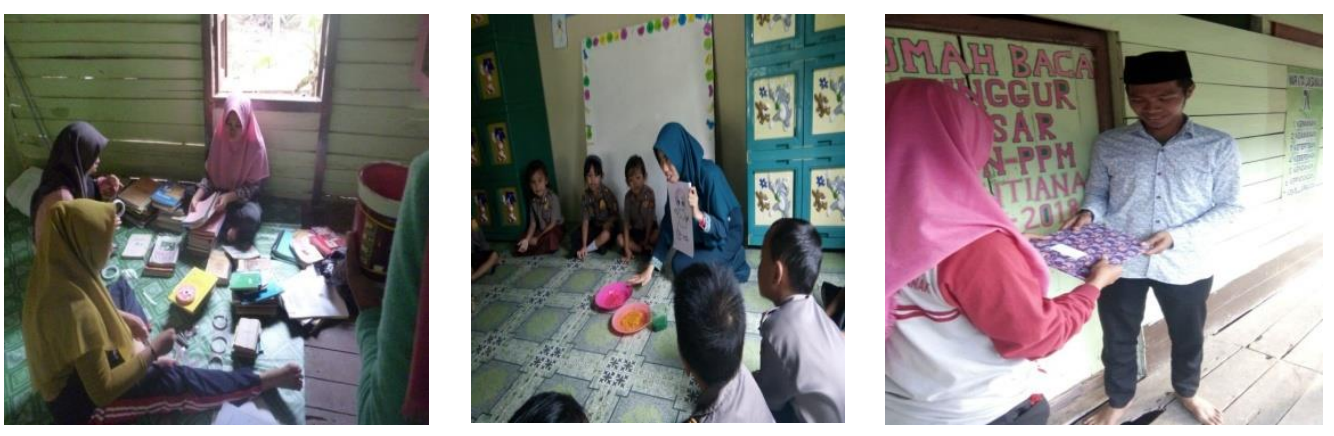

Gambar 2. Pelatihan pembuatan kolase, mozaik dan montase serta meronce

Hasil kegiatan ini adalah terbentuknya pondok pintar dan kader pengelola pondok pintar. Selain, itu, keterampilan guru PAUD juga meningkat setelah diberikan pelatihan. Para guru sudah terampil membuat media edukasi melalui media yang tersedia di alam, tanpa memerlukan biaya yang mahal.

\section{Simpulan Dan Rekomendasi}

Berdasarkan pelaksanaan yang sudah dilakukan dapat disimpulkan:

1. Kegiatan pendampingan, penyuluhan, dan pelatihan dapat meningkatkan pengetahuan/pemahaman masyarakat tentang pentingnya perilaku hidup bersih dan sehat serta menimbulkan kesadaran untuk memulai berperilaku hidup sehat.

2. Pembentukan pondok pintar dan kader pendidik dapat meningkatkan minat membaca anak-anak, dan membantu menanggulangi permasalahan dalam bidang pendidikan yang ada.

3. Pemerintah setempat diharapkan dapat menjadi motivator dan fasilitator bagi masyarakat dalam upaya peningkatan pemberdayaan masyarakat dan peningkatan potensi wilayah desa sehingga dapat terciptanya peningkatan derajat kesehatan masyarakat, sosial dan ekonomi di wilayah tertinggal 


\section{Jurnal Abdimas Mahakam \\ https://journal.uwgm.ac.id/index.php/abdimasmahakam \\ Online ISSN : 2549-5755 \\ Januari 2018, Vol. 2 No. 1}

\section{Daftar Pustaka}

Fitriana, R., Nur, D. R., \& Arbain, A. (2017). Pelatihan dan Simulasi IELTS bagi Mahasiswa dan Dosen di Lingkungan Fakultas Pendidikan dan Keguruan Program Studi Bahasa Inggris Universitas Widya Gama Mahakam Samarinda. Jurnal Abdimas Mahakam, 1(2), 88-95.

Mawan, A. R., Indriwati, S. E., dan Suhadi. (2017). Pengembangan Video Penyuluhan Perilaku Hidup Bersih dan Sehat (PHBS) Bermuatan Nilai Karakter Terhadap Peningkatan Pengetahuan Masyarakat Dalam Menanggulangi Penyakit Diare. Jurnal Penelitian: Teori, Penelitian dan Pengembangan, 2(7): 883-888.

Montgomery M.A. 2007. WATER and SANITATION in Developing Countries: Including Health in the Equation. Environmental Science \& Technology. 2007

Permatasari, A. O., and Sinuraya, R. K. (2017). Perbaikan Sanitasi Higienitas, dan Ketersediaan Air Bersih dalam Pencegahan Diare. Farmaka, 4(4): 1-6.

Profil Puskesmas Sungai Kakap, 2015

Selviana, Suwarni, L., and Fachri, H. (2018). The Primary Prevention Diseases Through Film on the Knowledge and Attitude of Elemntary School Students in the Isolated Area, Indonesia. SMU Medical Journal, 5(1): 106-144.

Suwarni, L., Selviana., and Fachri, H. (2016). Determinant of Environmental Disease in Health Promotion of Community Lead Total Sanitation (CLTS) on Elementary Students, SMU Medical Journal, 3(1): 352-361.

Yuswatiningsih, E. (2016). Pengetahuan dengan perilaku masyarakat tentang perilaku hidup bersih dan sehat. Jurnal Insan Cendekia, 3 (1). 